\title{
TRABALHADOR DOMÉSTICO: DA ORIGEM ESCRAVISTA À ATUAL IGUALDADE DE DIREITOS
}

\author{
Aline Fonseca Franco, Juliane Nagafugi de Souza Costa, Wesley Aparecido da Silva \\ Universidade do Oeste Paulista - UNOESTE, curso de Direito, Presidente prudente, SP. E-mail: \\ alinefonsecafranco@yahoo.com.br; wesley as.95@hotmail.com
}

\begin{abstract}
RESUMO
Trata o estudo de análise da Lei Complementar n. 150/2015, quanto à equiparação do trabalhador doméstico aos demais empregados urbanos e rurais. Desde a abolição da escravidão, o trabalhador doméstico sucedeu essa classe em suas atividades, entretanto os direitos relativos a eles pouco evoluíram. Após, paulatinamente, foram aprovadas leis regulamentadoras do trabalho doméstico. Contudo, somente em 2011 a Organização Internacional do Trabalho aprovou a Convenção n. 189, com o objetivo de estender aos domésticos os mesmos direitos dos demais trabalhadores. Consequência disso foi a aprovação da Emenda Constitucional n. 72/2013, que ampliou o rol de direitos trabalhistas. E, como passo mais recente, houve a aprovação da Lei Complementar n. 150/2015, com o principal objetivo de regulamentar os direitos conferidos pela Emenda Constitucional n. 72/2013. É visível a contribuição para reduzir juridicamente a discriminação até então existente, trazendo melhores condições de trabalho. Entretanto, no aspecto cultural a evolução não avançou tanto, restando ainda o preconceito advindo da origem do trabalho doméstico.
\end{abstract}

Palavras-chave:Trabalhador doméstico. Escravidão. Igualdade. Emenda Constitucional n. 72/2013. Lei Complementar n. 150/2015.

\section{DOMESTIC WORKER: FROM SLAVE ORIGIN TO THE CURRENT EQUAL RIGHTS}

\section{ABSTRACT}

This study analysis of Complementary Law n. 150/2015 on the equalization of the domestic worker to other urban and rural employees. Since the abolition of slavery, the domestic worker has succeeded this class in his activities, though the rights relative to them have hardly evolved. Afterwards, domestic labor regulation laws were passed. However, only in 2011 did the International Labor Organization 189, with the aim of extending to domestic workers the same rights as other workers. Consequently, the approval of Constitutional Amendment n. 72/2013, which expanded the list of labor rights. And, as a more recent step, the Complementary Law $n$. $150 / 2015$, with the main objective of regulating the rights conferred by the Constitutional Amendment $n .72 / 2013$. There is a visible contribution to legally reduce the discrimination that has existed before, bringing better working conditions. However, in the cultural aspect the evolution did not advance so much, still remaining the prejudice coming from the origin of the domestic work.

Keywords: Domestic worker. Slavery. Equality. Constitutional amendment n. 72/2013. Complementary Law n. 150/2015.

\section{INTRODUÇÃO}

Considerada como uma das profissões mais antigas da história, o trabalhado doméstico obteve grandes conquistasno decorrer de sua origem até os dias atuais, muitos direitos e garantias foram alcançados por meio de várias modificações legislativas, permitindo a constatação de uma 
grande evolução desde ausência de proteção legal durante o trabalho escravo até as condições de trabalho hoje garantidas juridicamente ao empregado doméstico.

Várias foram as normas que paulatinamente foram reduzindo a desigualdade existente entre os demais trabalhadores regidos pela CLT e os trabalhadores domésticos, os quais eram excluídos desse conjunto de leis trabalhistas.Foi com a Emenda Constitucional n. 72, de 2 de abril de 2013, que houve a extensão de algumas das garantias previstas no artigo 7으, da Constituição Federal, à categoria dos trabalhadores domésticos e, em junho de 2015, foi sancionada a Lei Complementar no 150 voltada diretamente para a categoria do trabalhador doméstico, que a partir daí passou a ter os mesmo direitos que os trabalhadores rurais e urbanos.

Neste sentido, a presente pesquisa tem por finalidade demonstrar a evolução histórica dos direitos dos trabalhadores domésticos e, de forma geral, pontuar algumas mudanças que a Lei Complementar 150/2015 trouxe a esta categoria profissional, utilizando o levantamento bibliográfico com abordagem qualitativa e método dialético dedutivo.

\section{EVOLUÇÃO HISTÓRICA DO TRABALHO DOMÉSTICO NO BRASIL}

A origem da utilização da força de trabalho no Brasil remonta à época do descobrimento com a chegada dos portugueses ao solo brasileiro, ocasião em que foi trazido um grande número de negros africanos, os quais, juntamente com os índios locais apreendidos, foram utilizados "para emprestarem, em regime de escravidão, sua força de trabalho" (SOUZA JUNIOR, 2015, p. 19), realizando atividades domésticas e de campo. Antes disso, as sociedades indígenas aqui existentes já realizavam suas próprias atividades domésticas.

O que parecia ser o primeiro passo para a evolução desse cenário escravagista, porém, não foi suficiente para trazer melhores condições de vida e autonomia para esses "trabalhadores", pois, segundo Antônio Humberto de Souza Junior (2015 p. 20), abolida a escravatura com a Lei Áurea em 1888, os recém-libertados, sem qualquer preparação para uma vida sem correntes, continuaram dependentes das atividades desempenhadas antes do firmado pela Princesa Isabel.

0 trabalho doméstico, até a edição das primeiras leis específicas regulamentadoras da prestação desse serviço, era regido pelas normas gerais do Código Civil sobre locação de serviços que, de modo geral, não previa qualquer segurança ou direito ao trabalhador.

A primeira lei de âmbito nacional a regular o trabalho doméstico foi o Decreto-Lei 3.078 de 1941, segundo o qual empregados domésticos seriam "todos aqueles que, de qualquer profissão ou mister, mediante remuneração, prestem serviços em residências particulares ou a benefícios destas" (artigo 10).

Esse diploma legal assegurava a anotação em carteira profissional, o aviso prévio e trouxe uma preocupação com o respeito à dignidade das pessoas envolvidas na relação de trabalho, evidenciando direitos e deveres do trabalhador doméstico.

Ato contínuo, em 1943, com o propósito de reunir em um só diploma legal todas as normas trabalhistas esparsas, promulgou-se a Consolidação das Leis do Trabalho (CLT), pelo Decreto 5.452/1943. Entretanto, este retrocedeu no campo da regulamentação do trabalho doméstico ao excluir propositadamente esta categoria profissional de suas disposições. Neste sentido, prevê até os dias atuais o artigo 70 da CLT:

Art. 70 - Os preceitos constantes da presente Consolidação salvo quando for em cada caso, expressamente determinado em contrário, não se aplicam:

a) aos empregados domésticos, assim considerados, de um modo geral, os que prestam serviços de natureza não econômica à pessoa ou à família, no âmbito residencial destas.

Contudo, o Decreto-Lei 3.078 de 1941 não foi expressamente revogado e, tratando-se de 
lei especial, continuou a reger, ainda que em um regime de proteção legal mínima, o trabalho doméstico.

Após isso, outras espécies normativas foram aprovadas, como: a) o Decreto-Lei 7.036/1944, que instituiu a lei acidentária para todos os trabalhadores, inclusive para os domésticos; b) a Lei 2.757/56, que desclassificou o doméstico quanto ao serviço realizado em condomínios residenciais não voltado aos moradores, que passaram à condição de empregados urbanos, destinatários de toda proteção conferida pela CLT; c) a Lei 4.090/62, que instituiu o décimo terceiro salário, intitulado de gratificação natalina, para todos os trabalhadores, inclusive aos domésticos; d) a Lei 5.859/72, que atribuiu como novos direitos dos domésticos o gozo de férias anuais remuneradas de vinte dias úteis e a filiação compulsória à Previdência Social; e) a Lei $7.418 / 85$, que instituiu o vale-transporte a todos os trabalhadores, inclusive aos domésticos.

Todavia, conforme ressalta Antônio Humberto de Souza Junior (2015, p. 29), um passo significativo para a inclusão dos trabalhadores domésticos no mundo normativo foi dado quando da promulgação da atual Constituição Federal, em 1988 (CF/88), que inovou, em seu artigo 70, parágrafo único, quanto aos direitos dessa classe, concedendo salário mínimo, irredutibilidade salarial, repouso semanal remunerado, terço de férias, licença-maternidade, licença-paternidade e aviso-prévio proporcional ao tempo de serviço, e ratificando as conquistas anteriores (décimo terceiro salário, filiação à Previdência Social, inclusive com direito à aposentadoria e férias anuais).

Fechando o ciclo, em 2006, com a Lei 11.324, conferiu-se às domésticas grávidas o direito à estabilidade desde a confirmação da gravidez até cinco meses após o parto, e garantiu a todos os domésticos trinta dias de férias, além de banir a possibilidade de descontos salariais por fornecimento alimentação, vestuário, higiene e moradia.

\section{O ATUAL CENÁRIO DOS EMPREGADOS DOMÉSTICOS NO BRASIL}

Em junho de 2011, foi aprovada pela Organização Internacional do Trabalho - OIT, a Convenção no 189, em Genebra, com o objetivo de conceder aos domésticos, os mesmos direitos aderidos pelos demais trabalhadores.O governo brasileiro, em 2013, ratificou a Convenção, adotando medidas para implementar as mudanças na legislação brasileira.

Assim, na sequência, como concretização dos termos assumidos, houve a aprovação da Emenda Constitucional (EC) n. 72/2013, que modificou substancialmente o rol de direitos trabalhistas (parágrafo único do artigo 7으, CF) a eles reconhecidos.

Foram estendidos a tais profissionais, dentre outros, os direitos: a) ao salário mínimo quando variável a remuneração; b) à jornada de oito horas diárias e quarenta e quatro semanais; c) às horas extras; d) FGTS (não mais facultativo); e) seguro-desemprego (não mais condicionado à "opção patronal" pelo recolhimento do FGTS); f) adicional noturno; g) salário-família.

Por fim, como passo mais recente no processo de equiparação dos direitos trabalhistas, foi promulgada a Lei Complementar (LC) n. 150 de 2015, denominada Lei do Trabalho Doméstico (LTD), com o fim de regulamentar os direitos conferidos aos domésticos por força da EC $n$. 72/2013. Entretanto, avançou para além desse objetivo, instituindo, em conjunto com a CLT e outras leis designadas, "um novo microssistema jurídico de regulação e proteção do trabalho doméstico no Brasil" (LEITE, 2015, p. 25).

Inclusive, quando citamos a CLT, o fazemos pelo fato de que, apesar de ela própria excluir do seu amparo os trabalhadores domésticos, como demonstrado anteriormente, a LC 150/2015 trouxe em seu artigo 19 que será ela aplicada de forma subsidiária aos empregados domésticos. Assim, apesar de não revogar expressamente o artigo 70, "a", da CLT, surge uma antinomia jurídica a ser esclarecida pelos critérios cronológico e da especialidade, ocorrendo revogação tácita, conforme entendimento de Carlos Henrique Bezerra Leite (2015, p.29).

A Lei do Trabalho Doméstico definiu trabalhador doméstico, em seu artigo 1ํ, como sendo "aquele que presta serviços de forma contínua, subordinada, onerosa e pessoal e de finalidade 
não lucrativa à pessoa ou à família, no âmbito residencial destas, por mais de 2 (dois) dias por semana".

Desse modo, integram, exemplificativamente, a categoria de trabalhadores domésticos, desde que preenchidos os requisitos acima expostos, o cozinheiro, a governanta, a babá, o vigia, o motorista particular, o caseiro, o acompanhante de idosos e etc.

Para garantir a igualdade entre as categorias dos trabalhadores foi instituído o regime qualificado de pagamento de tributos, de contribuições e demais encargos, instituto esse denominado de Simples Doméstico, que foi regulamentado 120 dias após a entrada em vigor da Lei Complementar n. 150/2015.

O sistema eletrônico de registro das obrigações previdenciárias e fiscais, assim como o de inscrição do empregador no Simples Doméstico, substituíram, de forma regulamentada, a obrigatoriedade de entrega de todas as informações, formulários e declarações a que estão sujeitos os empregadores domésticos, porque assegura o recolhimento mensal das contribuições mediante documento único de arrecadação, como explica Gustavo Filipe Barbosa Garcia (2017, p.272).

Com a inclusão do trabalhador no Simples Doméstico, ao realizar os recolhimentos dos tributos gerados pelo sistema, proporciona-se ao empregado garantias previdenciárias: "o empregado doméstico é segurado obrigatório da Previdência Social, sendo-Ihe devidas, na forma da Lei 8.213/1991, as prestações nela arroladas, atendido o disposto na Lei Complementar 150/2015" (GARCIA, 2017, p. 265).

A Constituição Federal de 1988 garante, em seu artigo 7ำ, inciso III, aos trabalhadores urbanos e rurais, o depósito mensal por parte dos empregadores de $8 \%$ de sua remuneração mensal para compor o Fundo de Garantia por Tempo de Serviço (FGTS), o qual foi instituído pela Lei 5.107/66, mas atualmente é regido pela 8036/90. Assim em uma eventual dispensa imotivada, o empregado tem uma "poupança" na Caixa Econômica Federal. Em relação ao trabalhador doméstico, a Lei 5859/72 estabelecia uma faculdade do empregador para incluir o trabalhador doméstico no FGTS e, somente com o advento da Lei Complementar 150/2015, é que se tornou obrigatório este recolhimento pelo empregador.

As regras trazidas pela Lei Complementar relativas ao Fundo de Garantia por Tempo de Serviço (FGTS) devido ao doméstico são basicamente iguais àquelas aplicáveis aos demais trabalhadores. A diferença está na multa havida em caso de rescisão contratual imotivada em que, nos casos de empregados regidos pela CLT, o empregador deverá pagar uma multa no valor de $50 \%$ do valor depositado, sendo $40 \%$ destinado ao empregado e $10 \%$ à União (Lei Complementar 110/2001) e, no caso trabalho doméstico, o empregador fica obrigado a recolher mensalmente a importância de 3,2\% da remuneração a título de multa de FGTS, conforme cita Ricardo Resende (2016, p.133).

Desse modo, o empregador doméstico não precisa ter um valor reservado para realizar a rescisão do empregado, pois já paga a indenização de forma mensal, "nas hipóteses de pedido de demissão, dispensa por justa causa ou término de contrato, o empregador movimentará o valor depositado referente à indenização" (RESENDE, 2016, p. 133). Portanto, o Simples Doméstico proporciona segurança a ambos os lados.

Importante destacar ainda que, buscando alcançar a igualdade entre os trabalhadores pela implementação do Simples Doméstico e pela obrigatoriedade do recolhimento mensal do FGTS, gerou-se a garantia do seguro-desemprego. Este direito era determinado ao empregado doméstico antes da Lei Complementar n. 150/2015, mas como o cadastro no fundo de garantia era facultativo o trabalhador perdia o direito ao seguro-desemprego no caso de dispensa imotivada pelo empregador.

Após outubro de 2015, quando o Simples Doméstico tornou-se efetivo, os empregados domésticos que contem com 15 meses de CTPS assinada e com recolhimento mensal dos tributos 
durante esse período, fazem jus ao seguro-desemprego, "o empregado doméstico que for dispensado sem justa causa fará jus ao beneficio do seguro-desemprego, na forma da Lei 7.998/1990, no valor de um salário mínimo, por período máximo de três meses" (GARCIA, 2017, p. 269).

Apesar dos avanços obtidos na tentativa de trazer mais igualdade entre os trabalhadores, relevo destacar uma diferença apontada por Gustavo Filipe Barbosa Garcia (2017, p. 273) existente entre o trabalhador regido pelas normas da CLT e que trabalha para pessoa jurídica, e o trabalhador doméstico que tem seus direitos assegurados na Lei Complementar n. 150/2015 e trabalha para pessoas físicas. Relata o autor que a diferença reside na fiscalização, na dificuldade quanto ao exercício das atividades de inspeção, pois os trabalhadores domésticos estão nas residências de seus empregadores e, de acordo com o artigo 5o, inciso XI, da Constituição Federal, "a casa é asilo inviolável do indivíduo, ninguém nela podendo penetrar sem o consentimento do morador, salvo em caso de flagrante delito ou desastre, ou para prestar socorro, ou durante o dia, por determinação judicial". Ou seja, para que ocorra a fiscalização, pelo Auditor-Fiscal do Trabalho, do cumprimento das normas que regem o trabalhador doméstico, no âmbito domiciliar do empregador, depende de agendamento e de entendimento prévio entre a fiscalização e o empregador.

Nessa linha, destacando ainda algumas diferenças entre as categorias de trabalhadores e a evolução pela busca da igualdade, LEITE (2015) menciona que a Emenda Constitucional 72/2013 tinha o sentido de equiparação, mas com palavras que determinavam o contrário quando discriminava os dispositivos que seriam aplicados exclusivamente ao doméstico, nas suas palavras: "por mais que a EC 72/2013 tenha prometido a "igualdade" entre o doméstico e os empregados urbanos e rurais, na essência essa mesma EC diz quais são os dispositivos do artigo 70 da CF aplicáveis à categoria" (LEITE, 2015, p. 31). Mostra-se, portanto, visível a limitação dos direitos dos trabalhadores domésticos na EC 72/2013, pois caso realmente fosse almejada a plena igualdade entre as categorias, a emenda constitucional garantiria todos os direitos previstos nos incisos do artigo 7으 da CF, assim como é garantido a todas as outras categorias.

Ainda com o advento da Lei Complementar 150/2015 não foi possível obter a plena igualdade entre as demais categorias de trabalhadores e os domésticos. Verificou-se, entretanto, que após a referida lei, a balança do direito passa a ter uma leve visão de equilíbrio, mas ainda há muito o que evoluir para se obter a real igualdade. A categoria dos trabalhadores domésticos ainda é vista de forma inferior a outras categorias, talvez pelo fato de serem pessoas que possuem uma formação escolar inferior, ou por ainda existir a concepção de que os trabalhadores que exercem funções em residência são ainda os "criados" do tempo da escravidão.

É bem antigo e forte o comando do artigo 5으, caput, da Constituição Federal, o qual garante a igualdade entre as pessoas em todos os sentidos, sem qualquer distinção, entretanto, no aspecto cultural, dada a sua origem do trabalho doméstico, o tratamento igualitário ainda não alcançou o trabalhador doméstico em sua plenitude.

\section{CONCLUSÃO}

O trabalho doméstico, após uma longa luta por igualdade, conseguiu equiparação jurídica com os demais empregados rurais e urbanos, ainda que com algumas diferenças em razão das particularidades de seus contratos de trabalho. Muitos foram os avanços obtidos ao longo dos anos, mas foi com a Lei Complementar 150/2015, que regulamentou a EC 72/2013 oriunda da ratificação da Convenção OIT 189, que passou a ser obrigatório o depósito do FGTS para o trabalhador doméstico e também garantido o seu direito ao seguro-desemprego.

Ao lado dos direitos dos empregados, surgiram deveres aos empregadores doméstico que deverão, por meio do sistema Simples Doméstico, recolher os tributos devidos, no qual se incluem 8\% para o FGTS; 3,2\% para fins de FGTS-multa rescisória e 0,8\% para financiamento do seguro 
contra acidentes do trabalho, conforme artigo 34 da LC 150/2015.

É, pois, visível que a Lei Complementar n. 150/2015 contribuiu para reduzir juridicamente a discriminação até então existente entre as demais categorias de trabalhadores, trazendo melhores condições de trabalho. Entretanto, no aspecto cultural, a evolução não avançou tanto, restando ainda o preconceito advindo da origem do trabalho doméstico, sendo verificado que o exercício desse trabalho ainda se dá por pessoas com baixa escolaridade. Nesse aspecto, social e cultural, a sociedade brasileira tem muito a evoluir.

\section{REFERÊNCIAS BIBLIOGRÁFICAS}

BRASIL, Constituição da República Federativa do Brasil de 1988. Disponível em: http:/www.planalto.gov.br/ccivil_03/Constituicao/Constituicao.htm. Acesso em 21 jul. 2017.

GARCIA, G. F. B. Curso de Direito do Trabalho. 11․ed. Rio de Janeiro: Forense, 2017.

RESENDE, R. Direito do Trabalho: Esquematizado. 6o.ed. São Paulo: Método, 2016.

SOUZA JUNIOR, Antonio Umberto de. O novo direito do trabalho doméstico. São Paulo: Saraiva, 2015.

LEITE, Carlos Henrique Bezerra; LEITE, Laís Durval; LEITE, Letícia Durval. A nova lei do trabalho doméstico. São Paulo: Saraiva, 2015. 